<smiles>O=C(O)c1ccc(NCc2nc3ccccc3[nH]2)cc1</smiles>

I<smiles>O=C(O)CCC(NC(=O)c1ccc(NCc2nc3ccccc3[nH]2)cc1)C(=O)O</smiles>

II

diethyl ester (m.p. $125^{\circ}$ ) by the condensation under similar conditions of 2-chloromethylbenziminazole and ethyl $p$-aminobenzoyl- $L$-glutamate (III). Hydrolysis with cold aqueous alcoholic sodium hydroxide gave the required acid (II), isolated as a hydrochloride, m.p. $201^{\circ}$ (found after drying at $100^{\circ}$ in a vacuum : $\mathrm{C}, 55 \cdot 6 ; \mathrm{H}, 4 \cdot 7 ; \mathrm{N}, 12 \cdot 6 ; \mathrm{Cl}, 8 \cdot 1$; $\mathrm{C}_{20} \mathrm{H}_{20} \mathrm{O}_{5} \mathrm{~N}_{4}, \mathrm{HCl}$ requires $\mathrm{C}, 55.5 ; \mathrm{H}, 4.9 ; \mathrm{N}, 12.9$; Cl, $8 \cdot 2$ per cent).

The $p$-aminobenzoylglutamic ester (IHI) is conveniently prepared by refluxing a solution of $p$-nitrobenzoyl chloride in benzene with ethyl glutamate hydrochloride, followed by catalytic reduction of the product. The $p$-aminobenzoylglutamic acid obtained by hydrolysis of (III) has m.p. $167^{\circ}$ and in $N$ sodium hydroxide solution, $[\alpha]_{D}^{220}=+29 \cdot 2^{\circ}$, comparable with the recorded value for the $D$-isomer of $[\alpha]_{D}=$ $-27 \cdot 4^{\circ}{ }^{3}$. Published accounts ${ }^{4}$ of the preparation of $p$-nitrobenzoylglutamic acid from glutamic acid recommend the use of excess $p$-nitrobenzoyl chloride. We have found that by the simultaneous addition of the acid chloride ( $1 \mathrm{~mol}$.) dissolved in dioxane and of an equivalent of $2 N$ sodium hydroxide to a solution of glutamic acid ( $1 \mathrm{~mol}$.) in its equivalent of $N$ alkali, $p$-nitrobenzoylglutamic acid of m.p. $114-116^{\circ}$ and $[\alpha]_{D}^{19 \circ}=+16 \cdot 9^{\circ}$ can be obtained in 70-80 per cent yield ${ }^{5}$. A full description of these experiments will be published in due course.

It has recently been found by Edwards, Starling, Mattocks and Skipper ${ }^{6}$ that the benziminazole (II) replaces 'folic acid' as a growth factor for Strep. foecalis R. (though at much higher concentrations), and also stimulates growth in presence of sub-optimal concentrations of folic acid. Similar experiments by us have, however, given different results. For Strep. foecalis R., grown in the improved medium of Rabinowicz and Snell', modified by the omission of glycine and asparagine and by the inclusion of pyridoxin (100 $\mu \mathrm{gm} . / 1$.$) , adenine and guanine (each 5 \mathrm{mgm} . / 1$.$) ,$ the benziminazole (II) $\left(10^{-9}\right.$ to $\left.10^{-3} \mathrm{M}\right)$ did not replace pteroylglutamic acid. Growth was measured turbid. imetrically after $20 \mathrm{hr}$. incubation at $37^{\circ}$. Nor was the organism stimulated in the presence of sub. optimal amounts of pteroylglutamic acid, but, on the contrary, under the latter conditions, growth was inhibited, although this inhibition was not observed when pteroylglutamic acid was added in amounts

\begin{tabular}{|c|c|c|}
\hline \multicolumn{3}{|c|}{$\begin{array}{l}\text { INHIBITION OF GROWTH OF Strep. facalis R. BY THE BENZIMINAZOLE } \\
\text { (II) IN PRESENCE OF PTEROYLOLUTAMIC ACID }\end{array}$} \\
\hline $\begin{array}{l}\text { Pteroylglutamic acid } \\
\text { (molar conc.) }\end{array}$ & $\begin{array}{l}\text { Benziminazole (II) } \\
\text { (molar conc.) }\end{array}$ & $\begin{array}{l}\text { Absorptiometer } \\
\text { reading * }\end{array}$ \\
\hline 0 & $10^{-s}$ to $10^{-0}$ & 0.00 \\
\hline $10^{-9}$ & 0 & 0.44 \\
\hline ,, & $10^{-7}$ & 0.43 \\
\hline ", & $10^{-5}$ & 0.37 \\
\hline ,", & $10^{-3}$ & 0.28 \\
\hline $2 \times 10^{-9}$ & 0 & $1 \cdot 05$ \\
\hline$-0 .>0$ & $10^{-4}$ & 0.82 \\
\hline ", & $10^{-3}$ & 0.52 \\
\hline $1 \cdot 6 \ddot{\times} 10^{-8}$ & 0 & $1 \cdot 57$ \\
\hline , & $5 \times 10^{-4}$ & $1 \cdot 50$ \\
\hline
\end{tabular}

* Averages of quadruplicate tubes after incubation for $20 \mathrm{hr}$. which afforded optimal growth in the absence of (II). Tests made with Lactobacillus casei, using the medium of Roberts and Snell ${ }^{8}$ and estimating growth turbidimetrically after incubation for $22 \mathrm{hr}$. at $37^{\circ}$ in an atmosphere of 95 per cent hydrogen, 5 per cent carbon dioxide, gave essentially the same results.

It is possible that the discrepancy between our results and those of Edwards et al. may be due to variations in the respective media. It is noteworthy that the medium used by the American experimenters gave measurable growth for Strep. foecalis $\mathrm{R}$. in the absence of added folic acid. Unlike that described by Edwards et al., which was acetate buffered and contained adenine, guanine, xanthine and uracil, the medium we have employed was buffered with citrate and contained neither xanthine nor uracil. In the light of recent work in this field ${ }^{9}$, differences in the pyrimidine-purine content of the two media may well be significant.

The simple benziminazole (I) also, when tested with Strep. foecalis R., was found to be inhibitory, though less so than compound (II), and was inactive as a substitute for pteroylglutamic acid.

Dyson Perrins Laboratory,

F. E. KING

P. C. Spensley

Department of Biochemistry,

R. H. Nimmo-Smith

University of Oxford. April 3.

Angier et al., Science, 103, 667 (1946); J. Amer. Chem. Soc., 70, 14 (1948).

${ }^{2}$ Bloom and Day, J. Org. Chem., 4, 14 (1939).

${ }^{3}$ Winter, J. Amer. Chem. Soc., 62, 3266 (1940).

- Auhagen, Z. physiol. Chem., 277, 197 (1943). Van der Scheer and Landsteiner, J. Immunol., 29, 371 (1935).

${ }^{5}$ Cf. Steiger, J. Org. Chem., 9, 396 (1944).

Science, 107, 119 (1948).

'J. Biol. Chem., 169, 631 (1947).

${ }^{8} J$. Biol. Chem., 163, 499 (1946).

Rogers and Shrive, J. Biol. Chem., 172, 751 (1948).

\section{The Sommelet Reaction}

Is a communication under this heading in Nature of May 8, p. 723, Messrs. Anyal and Rassach refer to a paper by Graymore and Davies ${ }^{1}$, in which it was shown that a mixture of benzylamine and formaldehyde gives benzaldehyde in good yield on heating in solution with hexamine. They say that, contrary to Graymore and Davies' findings, benzaldehyde can be obtained from benzylamine hydro. chloride in the absence of hexamine. In a later paper by Graymore ${ }^{2}$, it is shown that hexamine may be dispensed with, and benzaldehyde produced by heating methylene benzylamine (or, for that matter, a mixture of benzylamine and formaldehyde) with two-thirds of the quantity of hydrochloric acid, as required by the equation :

$\left(\mathrm{C}_{6} \mathrm{H}_{5} \mathrm{CH}_{2} \cdot \mathrm{N}: \mathrm{CH}_{2}\right)_{2}+2 \mathrm{HCl}=2 \mathrm{C}_{6} \mathrm{H}_{5} \cdot \mathrm{CH}_{2} \cdot \mathrm{N}: \mathrm{CH}_{2}, \mathrm{HCl}$.

It was hoped to obtain benzylidene methylamine from methylene benzylamine, but the attempt failed, the experiment resulting in the formation of benzaldehyde, methyl benzylamine and dimethyl benzylamine. Work is, however, still proceeding in this field.

JohN Graymore

Plymouth and Devonport Technical College. June 29.

'Graymore, J., and Davies, D. R., J. Chem. Soc., 293 (1945).

a Graymore, J., J. Chem. Soc., 1116 (1947). 